\title{
Hybrid double-valve replacement
}

Lloyd M. Felmly, MD, ${ }^{a}$ Scott D. Johnson, MD, ${ }^{a}$ Daniel H. Steinberg, MD, ${ }^{\mathrm{a}, \mathrm{b}}$ and Marc R. Katz, MD, MPH ${ }^{\mathrm{a}}$

From the ${ }^{\mathrm{a} D i v i s i o n}$ of Cardiothoracic Surgery, Department of Surgery; and ${ }^{\mathrm{b}}$ Division of Cardiology, Department of Medicine, Medical University of South Carolina, Charleston, SC.

Disclosures: Dr Steinberg is a consultant with Medtronic and Edwards. Dr Katz is a consultant with Abbott, Boston Scientific, and Medtronic. All other authors reported no conflicts of interest.

The Journal policy requires editors and reviewers to disclose conflicts of interest and to decline handling or reviewing manuscripts for which they may have a conflict of interest. The editors and reviewers of this article have no conflicts of interest.

Received for publication Dec 11, 2019; revisions received Dec 11, 2019; accepted for publication Feb 20, 2020; available ahead of print March 3, 2020.

Address for reprints: Marc R. Katz, MD, MPH, 30 Courtenay Dr, MSC 295, Room BM 282, Charleston, SC 29425 (E-mail: katz@musc.edu).

JTCVS Techniques 2020;2:36-7

2666-2507

Copyright (C) 2020 The Authors. Published by Elsevier Inc. on behalf of The American Association for Thoracic Surgery. This is an open access article under the CC BY-NC-ND license (http://creativecommons.org/licenses/bync-nd/4.0/).

https://doi.org/10.1016/j.xjtc.2020.02.016

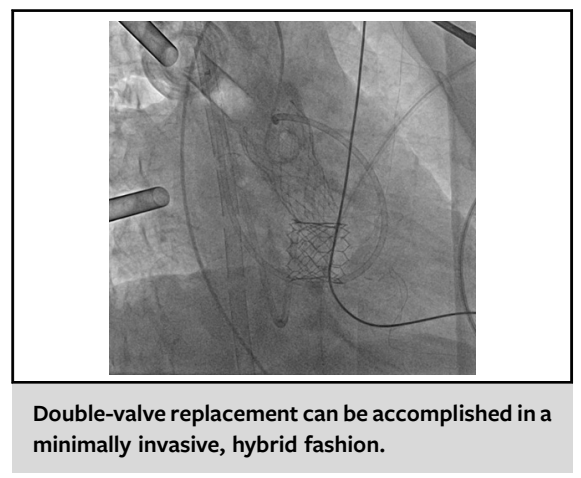

CENTRAL MESSAGE

Surgical placement of a trans-

catheter valve in mitral annular

calcification avoids pitfalls of

open and transcatheter

approaches.

Video clip is available online.

See Commentaries on pages 38,39 , and 41 .

The presence of mitral annular calcification (MAC) has been reported to increase risk of perioperative morbidity and mortality in mitral valve replacement (MVR). ${ }^{1}$ With the advent of transcatheter MVR, many patients with MAC have been treated successfully with transcatheter valve deployment. ${ }^{2}$ Access options include trans-septal, transapical, and transatrial. The "Achilles heel" of transseptal and transapical access is left ventricular outflow tract obstruction (LVOTO), as valve deployment may displace the anterior mitral leaflet into the ventricular outflow tract, causing hemodynamic compromise. Interventional techniques such as the intentional laceration of the anterior mitral leaflet procedure have been devised to address this complication in patients at high or extreme risk for surgery. ${ }^{3}$ For patients who are able to tolerate surgery, transatrial implantation of a transcatheter prosthetic allows for partial resection of the anterior leaflet to obviate the risk of LVOTO and valve implantation without debridement of calcium and subsequent risk of atrioventricular groove disruption. We herein report a surgical technique for minimally invasive, robot-assisted, transatrial mitral valve implantation using a balloon-expandable prosthetic.

\section{CASE REPORT}

An 84-year-old female patient with a history of hypertension, hyperlipidemia, rheumatic fever, aortic stenosis, and mitral stenosis and regurgitation presented with progressive fatigue and dyspnea. Transthoracic echocardiography revealed an ejection fraction of $71 \%$, mean aortic valve gradient of $27 \mathrm{~mm} \mathrm{Hg}$ with aortic valve area of $0.90 \mathrm{~cm}^{2}$, and mean mitral valve gradient of $23 \mathrm{~mm} \mathrm{Hg}$. Computed tomography revealed severe, circumferential MAC (Figure 1). Society of Thoracic Surgeons Predicted Risk of Mortality was $5.49 \%$ for aortic valve replacement (AVR) and $8.66 \%$ for MVR.

To minimize debridement of the mitral annulus and the risk of open surgery, the patient was offered minimally invasive, robotic-assisted deployment of a balloon-expandable valve in the mitral position, combined with transcatheter AVR. Preoperatively, her mitral valve was sized using measurements from her computed tomography scan (Figure 1). The procedure was undertaken in a hybrid operating suite. The left femoral vessels were cannulated for cardiopulmonary bypass. An Intraclude intra-aortic occlusion device (Edwards Lifesciences, Irvine, Calif) was used for clamping and cardioplegia (now recalled and suspended from use). The DaVinci SI system (Intuitive Surgical, Sunnyvale, Calif) was docked and used to access the left atrium. Robotic ports were 12 and $8 \mathrm{~mm}$, for the camera and arm ports, 


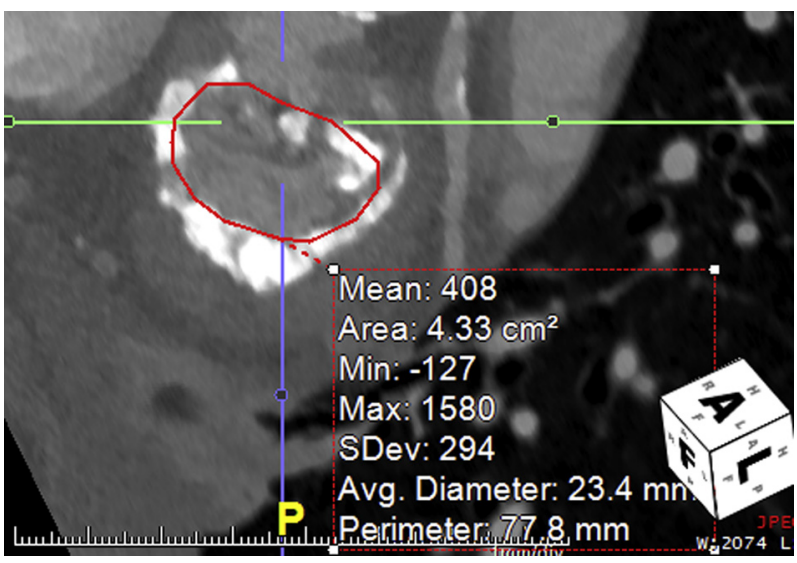

FIGURE 1. Preoperative CT reveals heavy annular calcification. Valve sizing is determined using the preoperative CT. If the appropriate valve size is unclear based on CT, a valvuloplasty balloon may be used to size the valve intraoperatively.

respectively, and a 2-cm incision was made for delivery of the valve.

As shown in Video 1, the A2 scallop of the mitral valve anterior leaflet was resected. Two felt strips were parachuted onto the mitral annulus over Gore-Tex sutures (W. L. Gore \& Associates, Newark, Del) to augment the landing zone and minimize perivalvular leak. These sutures were taken through the annulus where possible, and if prohibited by calcium, through the periannular atrial tissue. A 26-mm SAPIEN S3 valve (Edwards Lifesciences) was deployed, and the Gore-Tex sutures were secured to the struts of the valve stent. While on bypass, with the heart beating, right femoral access was obtained to deploy a 26-mm CoreValve Evolut R valve (Medtronic, Minneapolis, Minn) in the aortic position. Recovery was uneventful, and the patient was discharged home postoperative day 6 . Transthoracic echocardiography revealed an aortic valve gradient of $9 \mathrm{~mm} \mathrm{Hg}$ with trivial paravalvular regurgitation and a mitral valve gradient of $8 \mathrm{~mm} \mathrm{Hg}$ with no regurgitation. There was no LVOTO. The patient provided informed consent for the publication of the study data.

\section{DISCUSSION}

This surgical technique using a balloon-expandable prosthesis allows for mitral valve implantation in the setting of severe MAC with no debridement of the annulus, essentially obviating the risk of atrioventricular groove disruption. In fact, the heavy, concentric calcification is advantageous to this technique, as it provides a suitable landing zone for a transcatheter valve. It has become clear that transcatheter mitral valve strategies must account for the risk of LVOTO induced by displacement of the anterior mitral leaflet. In results from the transcatheter MVR in

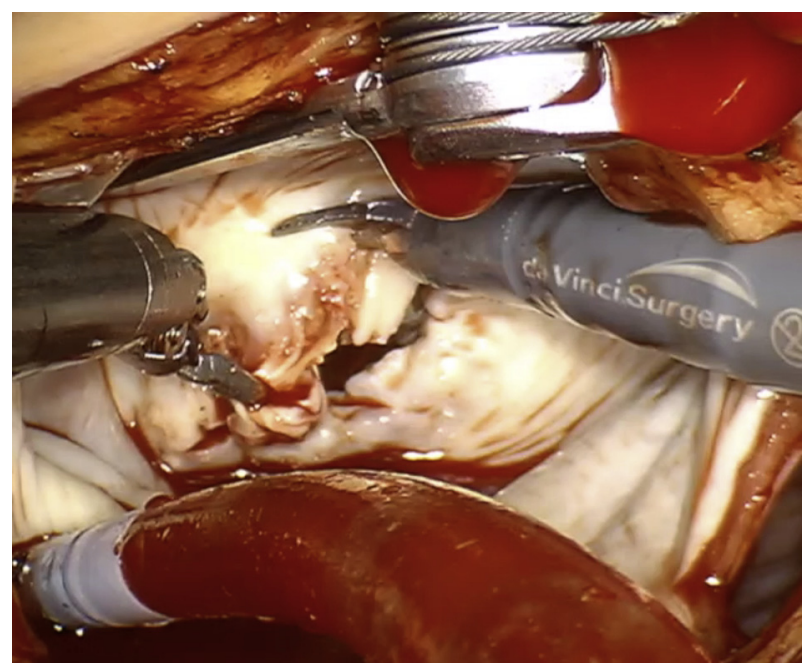

VIDEO 1. The video illustrates robot-assisted placement of a SAPIEN S3 valve (Edwards Lifesciences) within mitral annular calcium. Concomitant resection of the A2 scallop of the anterior mitral leaflet helps to prevent left ventricular outflow tract obstruction. Video available at: https://www.jtcvs. org/article/S2666-2507(20)30104-8/fulltext.

MAC Global Registry, 6 patients $(9.3 \%)$ suffered from postdeployment LVOTO, and subsequently 5 of those patients $(83.3 \%)$ died. ${ }^{4}$ The reported robot-assisted transatrial technique allows for partial resection of the anterior mitral valve leaflet to reduce the risk of LVOTO. In addition, it can be combined with other procedures without undue difficulty, as demonstrated in our concurrent replacement of the aortic valve via a transfemoral transcatheter AVR. In patients with severe MAC who can tolerate surgery, we believe this procedure offers the best option to replace the mitral valve successfully. Overall, this technique offers the opportunity to treat a severe disease with a reduced risk of complications, and it can be completed in a minimally invasive fashion, helping to reduce patient discomfort, length of stay, and recovery.

\section{References}

1. Cammack PL, Edie RN, Edmunds LH Jr. Bar calcification of the mitral anulus. A risk factor in mitral valve operations. J Thorac Cardiovasc Surg. 1987;94: 399-404.

2. Guerrero M, Urena M, Himbert D, Wang DD, Eleid M, Kodali S, et al. 1-year outcomes of transcatheter mitral valve replacement in patients with severe mitral annular calcification. J Am Coll Cardiol. 2018;71:1841-53.

3. Khan JM, Babaliaros VC, Greenbaum AB, Foerst JR, Yazdani S, McCabe JM, et al. Anterior leaflet laceration to prevent ventricular outflow tract obstruction during transcatheter mitral valve replacement. J Am Coll Cardiol. 2019;73: 2521-34.

4. Guerrero M, Dvir D, Himbert D, Urena M, Eleid M, Wang DD, et al. Transcatheter mitral valve replacement in native mitral valve disease with severe mitral annular calcification: results from the first multicenter global registry. JACC Cardiovasc Interv. 2016;9:1361-71. 